\title{
Linguistic pathway to multiplication
}

\author{
Katalin É. Kiss \\ Research Institute for Linguistics, \\ Hungarian Academy of Sciences \\ and Pázmány Péter Catholic University, Piliscsaba \\ e.kiss.katalin@nytud.mta.hu \\ Tamás Zétényi \\ University of Technology and Economics, Budapest \\ zetenyi@erg.bme.hu
}

\begin{abstract}
Whereas it is a well-established fact that young children can perform intuitive addition and subtraction, it is an open question whether they are capable of multiplicative operations on sets before receiving formal training. Earlier studies devoted to the study of intuitive arithmetic sought for evidence of intuitive multiplication in children's ability to distinguish proportional relations between quantities and numerosities. This paper claims that multiplication operations are present in children's everyday communication, in their understanding and producing sentences with two numerical quantifiers and a distributivity marker such as the Hungarian Mindhárom gyerek két autóval játszik 'Every one of three kids is playing with two cars', and Három gyerek két-két autóval játszik 'Three kids are playing with two cars apiece'. The paper gives account of an experiment testing how 5-7-year-old Hungarian children with no training in arithmetic operations interpret such sentences. The experiment shows that they have access to the multiplicative readings of distributive constructions; they not only accept them as true but at the age of 6-7 they can also actively compute the product of multiplication. The results also outline the acquisition path of multiplication, showing that children first multiply sets of concrete objects, then they represent the objects by their fingers, before they learn to manipulate sets mentally. Our results highlight the fact that language and mathematics are intertwined not only on the lexical level. Grammatical operations involving quantified expressions, among others, encode logical or mathematical operations on sets. Even if linguistic encoding is often ambiguous, grammatically encoded mathematical operations pave the way for abstract mathematics.
\end{abstract}

Keywords: intuitive multiplication; distributivity; acquisition of quantification; child language

\section{Introduction}

It is a well-established fact, confirmed by various experiments, that preschoolers, human infants, and even non-human primates can perform intuitive addition and subtraction (Dehaene 1997, chapter 2; Wynn 1992; Barth et al. 2005; 2006; 2008). Much less evidence has been put forth testifying 
that children are capable of multiplicative operations on sets before receiving formal training. McCrink and Spelke (2010) have demonstrated that preschoolers can perform doubling, quadrupling and increasing by 2.5 of large approximate numerosities, and a line of research has shown up multiplication in animals', infants', and children's recognition of proportional relations (Gallistel 1990; McCrink \& Wynn 2007; Schlottmann \& Tring 2005). Direct evidence of multiplication is hard to obtain in the visual domain generally used in acquisition tests. The solution of a multiplication task like Three kids each ate two apples; how many apples did they eat? involves the following steps: (i) the recognition that the set of two apples is the multiplicand, and three is the multiplier specifying how many copies of the multiplicand is to be generated; (ii) the generation of three copies of the two-apple set, (iii) the addition of the sets generated in step (ii). If the visual stimulus represents the three two-apple sets, the task becomes indistinguishable from multiple addition. That is why studies devoted to the study of intuitive arithmetic in the visual domain tend to seek for evidence of intuitive multiplication in children's ability to distinguish proportional relations between quantities and numerosities.

This paper will argue that multiplication operations are routinely performed by children prior to schooling; they are encoded by syntactic means in such doubly quantified sentences as the Hungarian examples in $(1 \mathrm{a}-\mathrm{c})$.

(1) a. Mind-három gyerek két autó-val játszik.

every-three kid two car-with plays

'Every one of the three kids is playing with two cars.'

b. Három gyerek is két autó-val játszik.

three kid DIST two car-with plays

'Three kids each are playing with two cars.'

c. Három gyerek két-két autó-val játszik.

three kid two-two car-with plays

'Three kids are playing with two cars apiece.'

We will report on an experiment testifying that 5-7-year-old Hungarian children accept such sentences as true statements about a situation involving three kids and six cars. At the age of 6-7, they can also actively set up situations representing the meanings of such sentences, i.e., they can compute the product of multiplication themselves. The results of the experiment also outline the acquisition path of distributive quantification, showing that children can access the distributive interpretation of sentences involving a quantified noun phrase and an indefinite before they can process sentences with two numerical quantifiers, and they carry out 
the procedure of multiplication at growing levels of abstractness, first multiplying sets of concrete objects, then their fingers, and eventually mental representations.

\section{Psychological background}

A large number of experiments have demonstrated beyond doubt that addition and subtraction form part of our toolkit of intuitive arithmetic, as not only preschoolers but also infants and even non-human primates can compute the outcomes of additive and subtractive operations over visually presented sets of elements; see, among others, Wynn (1992); Dehaene (1997, chapter 2); McCrink \& Wynn (2004); Barth et al. (2005); Flombaum et al. (2005); Cantlon \& Brannon (2007). Preschoolers have been shown to be capable of addition across modalities, adding up the numerosities of arrays of visual and auditory items (Barth et al. 2005; 2006; 2008). Animals', infants', and children's ability to add and subtract is based on their ability to represent approximate numerical magnitudes in an analog fashion (cf. e.g., Xu \& Spelke 2000; Slaughter et al. 2006; Barth et al. 2008; Cordes \& Brannon 2009).

It is less obvious whether children - let alone infants or non-human primates - relying on analog magnitude representations of approximate numerosities are capable of multiplicative operations on sets. The testing of multiplication is difficult in the visual domain because multiplication requires the generation of a certain number of copies of a set that have to be added up, and if the copies are provided by the visual stimulus, the task becomes indistinguishable from repeated addition. Some studies try to avoid this problem by testing the ability of animals, children, and mathematically untrained adults to detect ratios, i.e., specific proportional relations, between quantities and numerosities. Thus it has been pointed out that foraging animals are sensitive to differences in reward rates, and quickly adjust to rate changes to maximize their reward (see Gallistel 1990; Gallistel et al. 2006; Cordes et al. 2007), which suggests that they perform computation multiplying the average amount of food observed or obtained per food encounter with the number of food encounters per unit time (Gallistel 1990, 382). The same has been demonstrated for adults with no formal schooling, e.g., Brazilian fishermen (Nunes et al. 1993). Infants have also been shown to be sensitive to ratios. McCrink and Wynn (2007) found that six-month-old infants who had been habituated to a series of slides displaying large, changing numbers of objects of two types in a constant ratio noticed when their ratio changed. 
A number of studies have pointed out preschoolers' ability to detect proportional relationships. Schlottmann and Tring (2005) argued that 6year-old children choose between sure gain and gamble by calculating the ratio of risk and the amount at risk. Boyer et al. (2008) found that although children have difficulties solving proportional reasoning problems involving discrete units until 10 to 12 years of age, they can solve parallel problems involving continuous quantities by 6 years of age. Barth et al. (2009) investigated whether kindergarteners can identify halving and doubling over numerical and continuous values. They found that the children were capable of halving, but the results were inconclusive as regards doubling. In McCrink \& Spelke's (2010) experiment, 5-7-year-old children were given a task requiring a scalar transformation of large approximate numerosities. In a training block, children observed that a tinkling magic wand multiplied (doubled, quadrupled, or increased by 2.5) the array of objects shown on the computer screen. In the test trial, the product of multiplication was occluded, and children had to tell whether it was larger or smaller than a comparison set shown on the screen. In all conditions, children were able to represent the outcome of the transformation at above-chance levels.

In comparison to the large amount of robust evidence testifying that addition and subtraction form part of the biologically determined toolkit of humans (and even of higher animals), the evidence for the availability of multiplication for mathematically untrained children appears to be scant, and is limited to approximate magnitudes in the visual domain. We aim to show that the evidence is actually abundant; it is present in children's everyday communication, in their understanding and producing sentences with two numerical quantifiers and a distributivity marker enforcing a distributive interpretation.

Such sentences, e.g., Three kids each ate two cookies, contain a distributive key (in mathematical terms, a multiplier) and a distributed share (in mathematical terms: a multiplicand), and the interpretation involves the calculation of the product of multiplication by the listener. When processing such sentences, preschoolers, who have not learnt the multiplication table yet, cannot retrieve the product of multiplication; they have to calculate it. This operation is not merely multiple addition; it is a much more complex procedure. First, the multiplier and the multiplicand have to be identified. Then as many copies of the multiplicand have to be produced as the number of the multiplier. Eventually, the copies of the multiplicand have to be added up. Children who can process sentences of type (1a-c) are capable of performing this series of operations, i.e., they are capable of intuitive multiplication. 


\section{Linguistic background}

In natural language, multiplication is elicited by doubly quantified sentences, among others. A sentence with two quantifiers such as (2) can have at least three meanings, paraphrased in (2a), (2b), and (2c), two of which involve multiplication.

(2) Three kids are playing with two cars.

a. 'There are three kids, each of whom is playing with two (possibly different) cars.'

b. 'There are two cars, each of which three (possibly different) kids are playing with.'

c. 'There are three kids and two cars, and the former are are playing with the latter.'

The multiplicative interpretations in $(2 \mathrm{a})$ and $(2 \mathrm{~b})$ are called distributive readings. Under interpretation $(2 \mathrm{a})$, where three has scope over two (i.e., $3>2$ ), the sentence describes a situation with three kids and six cars. ${ }^{1}$ Under reading $(2 \mathrm{~b})$, where two has scope over three (i.e., $3<2$ ), the situation involves two cars and six kids. Under reading (2c), where both quantifiers have independent scopes, the situation involves three kids and two cars altogether. The latter meaning is called collective or cumulative depending on whether the whole group of kids is playing with the whole set of cars, or different members of the group of kids are playing with different members of the set of cars. Since this distinction is not relevant from our present perspective, it will be ignored, and reading (2c) will simply be referred to below as 'collective'.

Languages have means to enforce the distributive interpretation of doubly quantified sentences. They can mark either the so-called distributive key (the multiplier), or the distributed share (the multiplicand), or both. The Hungarian sentences in (3a) and (3b) mark the distributive key. In (3a), it is marked by the universal determiner mind 'every', whereas in (3b), it is marked by the distributive enclitic is:

(3) a. Mind-három néni két kutyá-t sétáltat.

every-three woman two dog-ACC walks

'Every one of three women is walking two dogs.'

b. Három néni is két kutyá-t sétáltat.

three woman DIST two dog-ACC walks

'Three women each are walking two dogs.'

${ }^{1}$ More precisely, it involves three kids and up to six cars, since the two cars assigned to the each of the three kids may partially or fully coincide. 
Is, the distributive clitic of (3b), is an additive particle; its distributivity arises from its additive function. An is-marked constituent modified by a numeral $n$ is understood as the collection of $n$ individuals each of which is involved in a separate subevent of the type described by the sentence part in the scope of the $i s$-marked phrase. Thus (3b) represents a situation with three women each of whom participates in a separate subevent of walking two dogs.

The distributive force of both the universal quantifier mind and the enclitic is is absolute in adult Hungarian. ${ }^{2}$ Thus (4) only has a distributive interpretation, with every member of the subject set lifting a separate piano, no matter how improbable this reading is pragmatically.

(4) Mind az öt fiú/ öt fiú is fel-emelt egy zongorá-t.

every the five boy five boy DIST up-lifted a piano-ACC

'Every one of the five boys lifted up a piano.'

The distributivity of a Hungarian doubly quantified sentence can also be marked on the distributed share, by numeral reduplication:

(5) Három néni két-két kutyá-t sétáltat.

three woman two-two dog-ACC walks

'Three women are walking two dogs apiece.'

Notice that két-két kutya 'two-two dogs' does not mean two times two dogs; it means multiple times two dogs, where the exact number of multiplication is specified by a structurally higher quantified expression functioning as the distributive key.

In Hungarian, scope interpretation is also facilitated by syntactic structure. Quantifier scope marking has mostly been grammaticalized, i.e., surface syntax disambiguates scope (Hunyadi 1986; É. Kiss 1991; 1994; 2002; 2010; Szabolcsi 1994; 1997; Szabolcsi \& Brody 2003; Surányi 2002; 2006 ; etc.). Quantifiers entering into scope interaction are raised into preverbal positions in most cases, and the wider scope quantifier, functioning

${ }^{2}$ In fact, is can also function as the English too, adding the event described by the sentence to a previous similar event. Thus (3b) could also mean 'Three women, too, are walking two dogs'. In this case the event of three women walking two dogs is added to some previously mentioned or situationally given event of individuals walking dogs. Under this reading, the distributive key interpretation of három nô 'three women' with respect to the set of three dogs is not obligatory. This reading of $i s$, however, only arises in a specific context or situation - whereas the examples we used in our experiments were out-of-the-blue sentences. 
as the distributive key, is always prior the distributed share both in linear order and in the structural hierarchy.

\section{Distributive scope in child language}

Aspects of distributive scope interpretation in child language have been investigated by a number of former experiments, but these experiments only tested children's passive acceptance of distributive readings, and their results were not related to the issue of intuitive multiplication.

Brooks and Braine (1996) examined if 4-10 year old children were able to assign collective and distributive interpretations to sentences containing a universal quantifier and an indefinite such as All of the men are building a boat and Each man is building a boat. The experiments involved forced choice between the visual representations of the two interpretations, that is, they tested children's passive understanding of distributivity. The results show that children can assign both the collective and the distributive readings to both types of sentences. A control sentence in one of the experiments, Three men are building a boat, contained a numerically modified subject (but no distributivity marker). Brooks and Braine found that 4year-olds chose randomly between its collective and distributive readings, but around the age of five they started to display a growing preference for its collective interpretation. What is important for us in the present context is that children as young as 4 years of age gave evidence of understanding both the potential distributivity of sentences containing a quantified noun phrase and an indefinite, and the procedure of multiplication that distributivity involves - even if the examples only required multiplication by one.

Pagliarini et al. (2012) studied the ability of 4-13-year-old Italian children to assign distributive readings to sentences containing a non-quantificational plural subject and an indefinite object (such as The girls are building a snowman). In the control condition, the definite article of the subject was replaced by an each-type determiner. Pagliarini and her colleagues used truth value judgement tasks, i.e., they, too, tested children's passive understanding of distributivity. They found that the distributive interpretation of non-quantificational plural subjects decreased, whereas the distributive interpretation of each-subjects increased with age.

Syrett and Musolino (2013) tested the interpretation of sentences like Two boys pushed a car; Each boy pushed a car, and their passive counterparts by children aged $5-7$. In three experiments, children had to judge the truth value of sentences associated with events presented as video 
recordings, and a fourth experiment involved a forced choice between two static visual representations. Syrett and Musolino's experiments resemble previous experiments in that they tested the passive understanding of distributivity, and investigated the interpretation of sentences where one of the noun phrases entering into scope interaction was an indefinite, i.e., where one of the factors of multiplication was 1 . Their results confirmed the results of Brooks \& Braine (1996) and Pagliarini et al. (2012), i.e., preschoolers are aware of the possibility of the distributive interpretation of indefinites in the scope of a numerically quantified noun phrase. An interesting observation of the study is that the addition of lexical elements such as each and together does not significantly change children's acceptance patterns.

Musolino (2009) tested preschoolers' scope interpretation of sentences containing two numerically modified noun phrases (Two boys are holding three balloons), and sentences containing a numerically modified noun phrase and an each-phrase ( Two boys are holding each balloon). Musolino's experiments, too, consisted of truth value judgement tasks, i.e., he, too, tested children's passive knowledge of distributivity. However, the tasks were more complex than those of the experiments discussed above as both of the noun phrases contained a definite numeral. Since in English, the scope order of quantifiers need not coincide with their linear order, the test sentences were ambiguous in multiple ways. In addition to the collective/ cumulative readings, they also allowed two distributive interpretations, which differed in the choice of the distributive key and the distributed share. The results show that preschoolers can assign both collective and distributive readings to both types of sentences (though they disprefer the distributed share interpretation of an each-phrase in object position). Crucially, children readily accept sentences like Three boys are holding two balloons if the total number of balloons, six, is different from the one mentioned in the sentence, two.

É. Kiss et al. (2013) tested by truth value judgement, forced choice, and act-out tasks how Hungarian preschoolers interpret sentences containing two noun phrases modified by definite numerals, and a distributive particle (is). The results led to the following major claims: (i) Hungarian preschoolers have access to the multiplicative reading of doubly quantified sentences. (ii) At the same time, children's strategies of interpreting the scope order of doubly quantified sentences are less constrained than those of adults. Their selection of the multiplier and the multiplicand may depend not only on the linear order of the quantified expressions, but also on their thematic prominence relation, and/or the visual representa- 
tion/grouping of the sets denoted by them. (iii) Of the multiplicative and collective readings of a doubly quantified sentence, children choose the multiplicative reading only when pragmatics makes the collective reading implausible.

In a follow-up experiment, É. Kiss and Zétényi (2017) sought to answer the question of why Hungarian children's scope interpretation of doubly quantified sentences is not isomorphic, i.e., why they accept readings in which the scope order of quantifiers is the opposite of their linear order - even though non-isomorphic scope interpretation is absent from adult Hungarian. The results of an act-out task, as well as reaction time data indicated that the default reading of doubly quantified sentences for Hungarian preschoolers is the collective reading (also in the presence of the distributive clitic is), which they are willing to revise only under strong pragmatic pressure. The assumption that the distributive reading is a second attempt at sentence interpretation, and is, therefore, dissociated from the linear flow of speech, explains why the linear order of the two quantifiers does not necessarily determine scope order.

\section{Experiment}

Whereas the experiments surveyed in Section 4 only tested the passive understanding of the distributive interpretation of sentences with a quantifier and an indefinite, or two quantifiers, our experiment to be presented below aimed to find out whether children with no math education can actively carry out the procedure of multiplication encoded by such sentences. Therefore, we asked children to act out the meanings of doubly quantified distributive sentences by means of toy figures. We wanted to test if they can calculate the product of multiplication, hence before the act-out we asked them the question how many figures we should hand them from the toy box; how many figures they would need to set up the situation. We opted for act-out because it eliminates the possibility of children giving correct answers by chance, without going through the multiplication process.

\subsection{Participants}

We tested 101 children, 63 preschoolers from two Budapest kindergartens, and 38 first graders from a Budapest primary school in the fall of the schoolyear when they began school. The preschoolers belonged to two age 
groups: younger kids and older kids. The group of younger kids included 31 children, 12 boys and 19 girls; their mean age was 4;10, the age range was 4;3-5;5, SD: 4 months. The older kids' group included 32 children, 18 boys and 14 girls; their mean age was $6 ; 2$, the age range was 5;7-6;9, SD: 4 months. The group of first graders included 38 children, 15 boys, 23 girls; their mean age was $7 ; 1$, the age range was $6 ; 5-7 ; 6$, SD: 3 months. We aimed to test children who had not received any training in multiplication. Arithmetic is not part of the curriculum of Hungarian kindergartens; they only learn the numbers from 1 to 10, and practice relations like 'more' and 'less'. We tested first graders after 3 months of school. The official math curriculum (http://ofi.hu/letoltheto-tanmenetek) of these three months includes the notions and the representations of the numbers to 9 , and the notions of 'more', 'less', and 'same'. The operations of addition and subtraction to 9 are also introduced but are not drilled yet.

\subsection{Materials and methods}

\subsubsection{Warm-up task}

The experiment began with a warm-up excercise asking for truth value judgements. The children were shown 11 sentence-picture pairs, including six doubly quantified cases and five fillers. The doubly quantified sentences were of type $(1 \mathrm{a}-\mathrm{c})$, paired with pictures showing their distributive readings. For example:

(6) Mind a három tornyo-t két fiú építi.

every the three tower-ACC two boy builds

'Every one of the three towers are being built by two boys.'

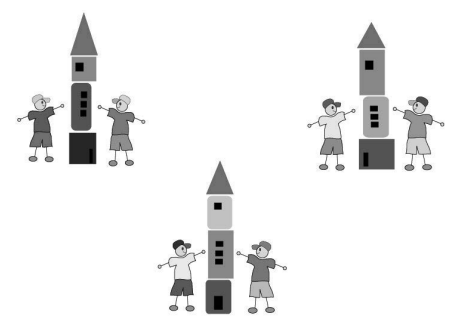

Figure 1: Picture for sentence (6) 
(7) Három kislány is két virágo-t locsol. three girl DIST two flower-ACC waters 'Three girls each are watering two flowers.'

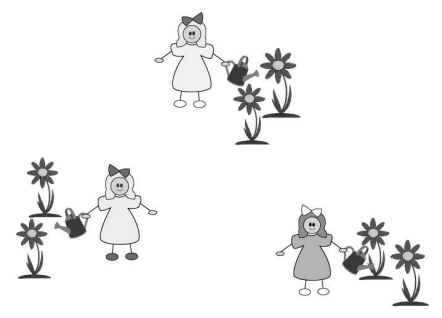

Figure 2: Picture for sentence (7)

(8) Két markoló három-három gödrö-t ás. two excavator three-three hole-ACC digs 'Two excavators are digging three holes apiece.'
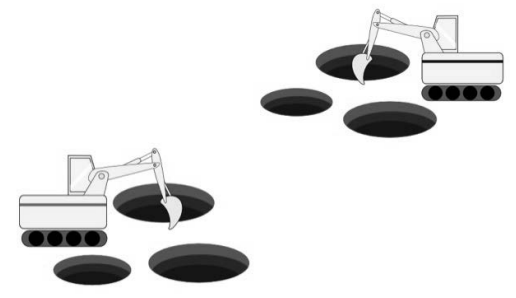

Figure 3: Picture for sentence (8)

The test sentences were all true of the visual representations associated with them, whereas four of the five fillers were false.

The warm-up excercise had two goals. It served to identify and to exclude the children who did not cooperate at all, or said yes to every stimulus, including obviously false fillers. We had to exclude five preschoolers. The visually represented distributive situations used in the introductory 
excercise also served the purpose of bringing the possibility of distributive interpretations to the working memory of children. We regarded this necessary because a previous series of experiments (É. Kiss et al. 2013; É. Kiss \& Zétényi 2017) showed that children's primary, default interpretation of sentences containing two numerical quantifiers and the distributive particle $i s$ is the collective interpretation. A distributive reading represents the revision of the collective interpretation, and such a revision is elicited by strong pragmatic cues. What we aimed to achieve by the distributive sentence-picture pairs of the warm-up phase was that children be aware of the distributive option also in lack of a suggestive context or situation.

\subsubsection{Act-out task}

After the introductory truth value judgement task, the children had to act out a semi-randomized series of six test sentences and three fillers. The test sentences were doubly quantified sentences with a distributivity marker, including two examples of each of the three types illustrated in $(2 \mathrm{a}-\mathrm{c})$. We tested all three types because we hypothesized that the linguistic realization of the distributivity marker might be a factor affecting children's achievement. Mind 'every', the general universal quantifier, may be the most familiar distributivity marker for children. The particle is may be more difficult for them because of its ambiguity. It functions as a distributive-key marker when it is cliticized to a numerically modified noun phrase; in other contexts, however, it is an additive particle (see footnote 2). Numeral reduplication may be misleading for young children because they may interpret it iconically, as the signal of duplication for instance, they may interpret három-három 'three-three' as 'two times three', instead of 'multiple times three'.

The fillers were distributive sentences where the distributed share was an indefinite. That is, children were given the stimuli in (9)-(12).

(9) a. Mind a három maci két cukorká-t kapott. every the three bear two candy-ACC got 'Every one of the three bears got two candies.'

b. Mind-két ember-nek három malac-a van. every-two man-DAT three pig-POSs.3SG is 'Both men have three pigs.' 
(10) a. Két fá-nál is három bárány álldogál. two tree-at DIST three lamb stands

'At each of two trees, three lambs are standing.'

b. Három néni is két kutyá-t sétáltat.

three woman DIST two dog-ACC walks

'Three women each are walking two dogs.'

(11) a. Két autó-t négy-négy maci tol.

two car-ACC four-four bear pushes

'Two cars are being pushed by four bears apiece.'

b. Három kutya két-két bárány-ra vigyáz.

three dog two-two lamb-SUBLAT gards

'Three dogs are shepherding two lambs apiece.'

The fillers, involving a single quantified expression and an indefinite, involved multiplication by one:

(12) a. Mind az öt bácsi-nak van autó-ja.

every the five man-DAT is car-POSs.3SG

'Every one of the five men has a car.'

b. Két bárány-t kerget egy-egy kutya.

two lamb-ACC chases one-one dog

'Two lambs are being chased by one dog apiece.'

c. Négy gyerek kapott egy-egy cukorká-t.

four child got one-one candy-ACC

'Four children got one candy apiece.'

The fillers served the purpose of making the set of numbers occurring in the tasks more varied, less prone to priming effect. The test sentences did not allow much variation. We wanted to elicit multiplication where the product is not identical with the multiplier or the multiplicand, and where the product cannot be obtained by the addition of the multiplier and the multiplicand, hence we avoided examples where one of the factors is 1 , or both factors are 2 . At the same time, we did not want to transgress the number range of 4-6-year-old preschoolers, hence most of our test examples involved $2 \times 3$ or $3 \times 2$, and one of them involved $2 \times 4$. Owing to the fillers, the product of the multiplication was different from that in the previous example in each case. 


\subsection{Procedure}

\subsubsection{Warm-up task}

The child, the experimenter, and a helper were seated at a table in front of a laptop in a quiet room of the kindergarten. The experimenter told the child that first they would watch pictures on the computer. He explained that the helper looked at the pictures beforehand, and recorded what she saw, but she did not wear her glasses and sometimes did not see the picture properly. The child should tell about each sentence if it is true of the picture shown on the computer. If the sentence is false, she should correct it.

\subsubsection{Act-out task}

After this warm-up block, the experimenter put the computer aside, and told the child that they would play. He would tell the child a sentence, and she should set it up with the toy figures in the box in front of the helper. Then the experimenter uttered one of the sentences in (9)-(12). After hearing the sentence, the helper gave the child the toys denoted by the initial, wide-scope quantified expression, and then asked how many items the child would need of the figures corresponding to the second quantified expression. For example, after listening to (9a), the Hungarian equivalent of 'Every one of the three bears got two candies', she gave the child three bears, and asked: Hány cukorkát adjak? 'How many candies shall I give you?' or: Hány cukorkára van szükséged? 'How many candies do you need?'.

The test sentences and the fillers were presented in a predetermined semi-randomized succession, and half of the children received the series of sentences in the reverse order. The helper recorded the child's answers on a sheet of paper. The sessions were also video-recorded.

\subsection{Results}

\subsubsection{Warm-up task}

In the truth value judgement task of the warm-up phase, the mean success rate was around $90 \%$ in all three age groups (92\% in the case of younger kids, $87 \%$ in the case of older kids, and $91 \%$ in the case of first graders). Of the three distributivity markers, the universal quantifier proved to be easiest to interpret ( $96 \%$ of the children understood it correctly). In the case of sentences with the particle $i s$, the mean succes rate was $88 \%$, whereas in the case of numeral reduplication, it was $84.5 \%$. 


\subsubsection{Act-out task}

As shown in (9)-(11), each of the three types of doubly quantified distributive constructions to be acted out was represented by two sentences. Children's reactions to the pairs of sentences of the same type significantly correlated $((9 \mathrm{a}, \mathrm{b}): r=0.51, p<0.001 ;(10 \mathrm{a}, \mathrm{b}): r=0.37, p<0.001$; (11a,b): $r=0.57, p<0.001)$, hence we added up their scores. Thus the maximum score for each sentence type was 2 .

The means (and standard deviations) of the answers to the sentences containing mind: younger kids: 0.71 (0.86); older kids: 1.34 (0.83); first graders: 1.42 (0.72). The means (and standard deviations) of the answers to the sentences with is: younger kids: 0.61 (0.76); older kids: 1.06 (0.84); first graders: 1.34 (0.75). The means (and standard deviations) of the answers to the sentences with numeral reduplication: younger kids: 0.48 (0.77); older kids: 0.97 (0.86); first graders: 1.47 (0.76).

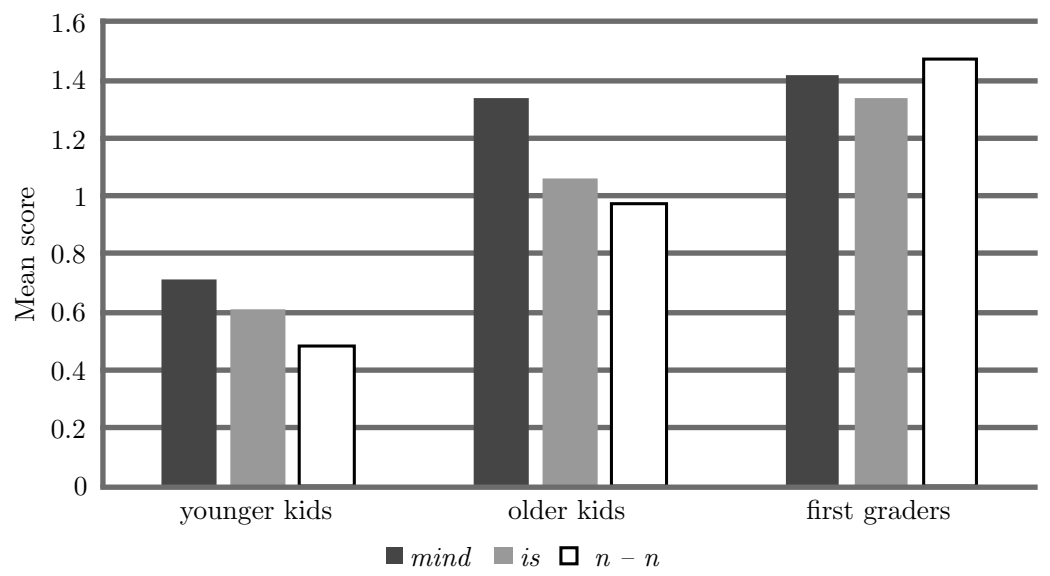

Figure 4: Mean scores of the three types of distributive sentence pairs

As demonstrated by Figure 4, the mean score increased with age for each sentence type. The Kruskal-Wallis test shows the growth to be statistically significant: Chi-square $(\mathrm{df}=2)=12.85, p=0.002$ in the case of sentences containing mind; Chi-square $(\mathrm{df}=2)=13.19, p<0.001$ in the case of sentences containing $i s$, and Chi-square $(\mathrm{df}=2)=21.26, p<0.001$ in the case of sentences containing numeral reduplication $(n-n)$. The three age groups also differ from each other by considering all the three conditions together: Chi-square $(\mathrm{df}=2)=18.86, p<0.001$. 
The mean ages of those giving 0 , or 1 , or 2 correct answers differed significantly by sentence types: $F_{\mathrm{ANOVA}}(\mathrm{df}=1 / 100)=9.92, p<0.001$ in the case of mind-sentences; $F_{\mathrm{ANOVA}}(\mathrm{df}=1 / 100)=7.82, p=0.001$ in the case of $i s$-sentences; $F_{\mathrm{ANOVA}}(\mathrm{df}=1 / 100)=15.23, p<0.001$ in the case of sentences containing numeral reduplication $(n-n)$.

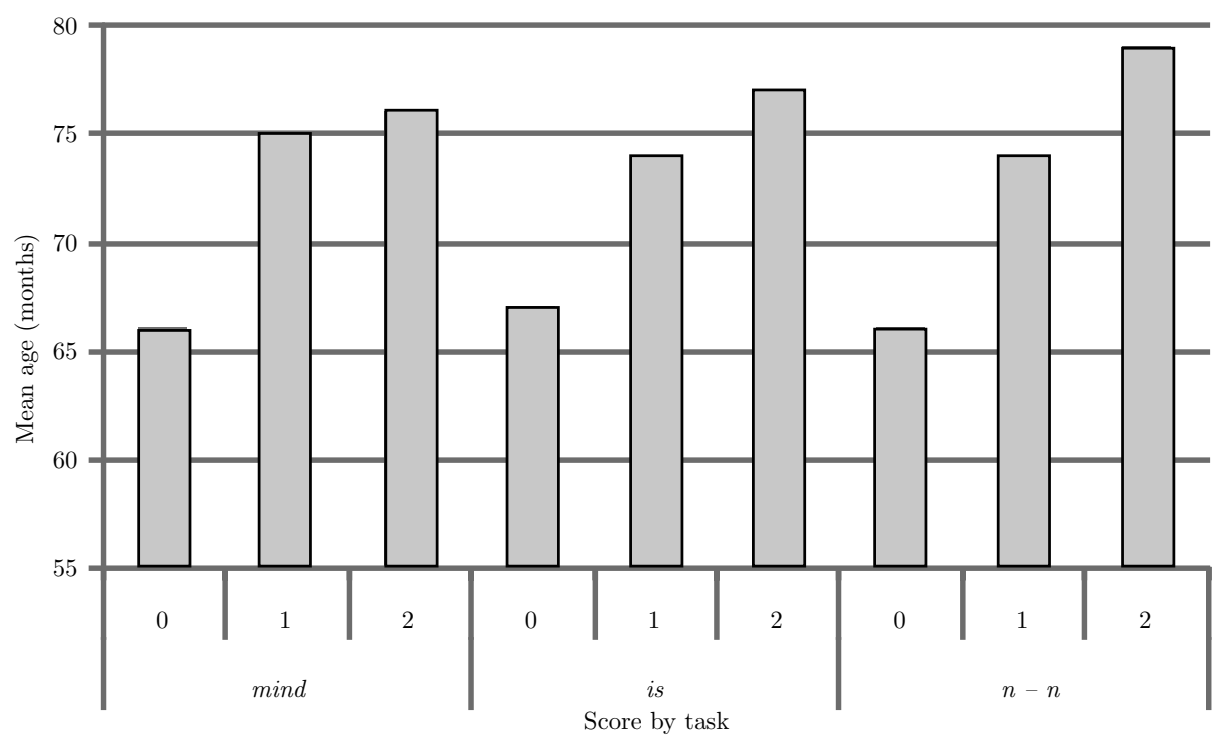

Figure 5: The mean ages of children achieving 0,1 , and 2 scores

The summary of the results of the three age groups achieved in all three tasks shows that the younger kids (mean age $4 ; 10$ ) solved $30 \%$ of the tasks successfully. The success rate of the older kids (mean age $6 ; 2$ ) was $56 \%$, whereas the success rate of the first graders (mean age: $7 ; 1 \%$ ) was $71 \%$.

We observed three strategies of calculating the product of multiplication among the participants giving correct answers. $24 \%$ of them solved the tasks by multiplying the set of real objects representing the multiplicand, and counting their sum. Thus when the child heard, for example, the sentence Három néni is két kutyát sétáltat 'Three women each are walking two dogs', and was asked How many dogs do you need?, she set up three women in front of her, and asked for two dogs, then for two more dogs, and again for two more dogs, before announcing: I need six dogs. $30 \%$ of the children giving correct answers multiplied sets of their fingers, instead of sets of objects. Thus after listening, for example, to the stimulus meaning 'Three women are walking two dogs', they stretched out three times two 
fingers, and counted them (usually silently). $46 \%$ of the children giving correct answers were able to calculate the result of multiplication mentally, without the help of their fingers.

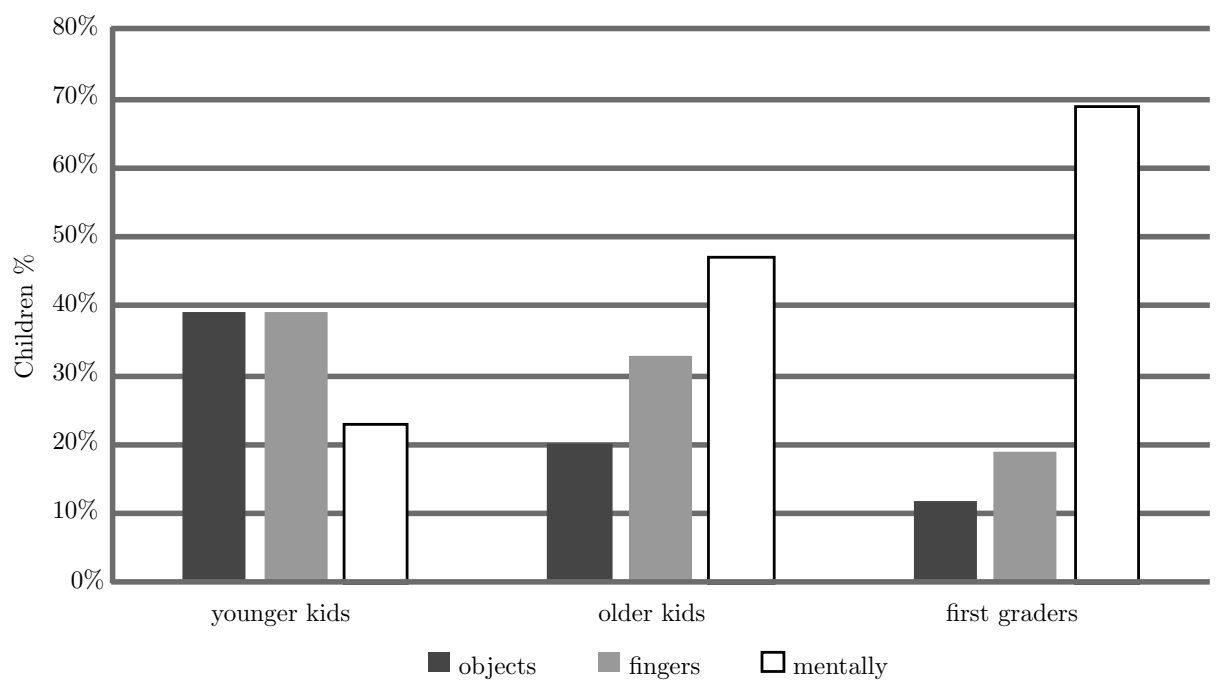

Figure 6: Strategies of calculating the product of multiplication

The proportions of the three strategies changed with age: $70 \%$ of the first graders answering correctly performed mental calculations, which was used only by $47 \%$ of the older kids and $25 \%$ of the younger kids. The younger kids mainly reached the solution by finger counting or by manipulating the objects (39-39\%). As mental calculation becomes more and more available for kids by ageing, they need less and less "outer help" (objects and fingers) to succeed.

Most children not giving the expected response answered by repeating either the last number or the initial number of the stimulus.

We measured the reaction times of the answers, i.e., the time span between the offset of the helper's stimulus question and the onset of the child's answer in the video-recording. The reaction times of the answers to the two sentences representing the same type of distributive construction were added up. The Kruskal-Wallis test showed significant differences between the reaction times of the answers scoring 1 or 2 (labelled below as "1-2 "answers) and the answers scoring 0 (labelled below as " 0 " answers) in all the three sentence types: Chi-square $(\mathrm{df}=1)=7.65, p<0.001$ in the case of sentences containing mind; Chi-square $(\mathrm{df}=1)=18.27, p<0.001$ 
in the case of sentences containing is, and Chi-square $(\mathrm{df}=1)=13.89$, $p<0.001$ in the case of sentences containing numeral reduplication $(n-n)$. The reaction time data for the sentences including mind: Mean $_{0}=6.51 \mathrm{sec}$ $(S D=8.58), M_{e a n}-2=15.12 \sec (S D=11.91)$, for the sentences including is: Mean $_{0}=4.18 \sec (S D=3.32), \operatorname{Mean}_{1-2}=11.39 \sec (S D=9.65)$ and for the sentences including $n-n: \operatorname{Mean}_{0}=5,37 \sec (S D=3.74)$, $\operatorname{Mean}_{1-2}=11.63 \sec (S D=9.32)$. That is, incorrect answers, which usually pick up one or the other quantifier from the stimulus sentence, come early. Good answers, i.e., the correct calculations of the product of multiplication, take time to arrive at in all the three types of tasks.

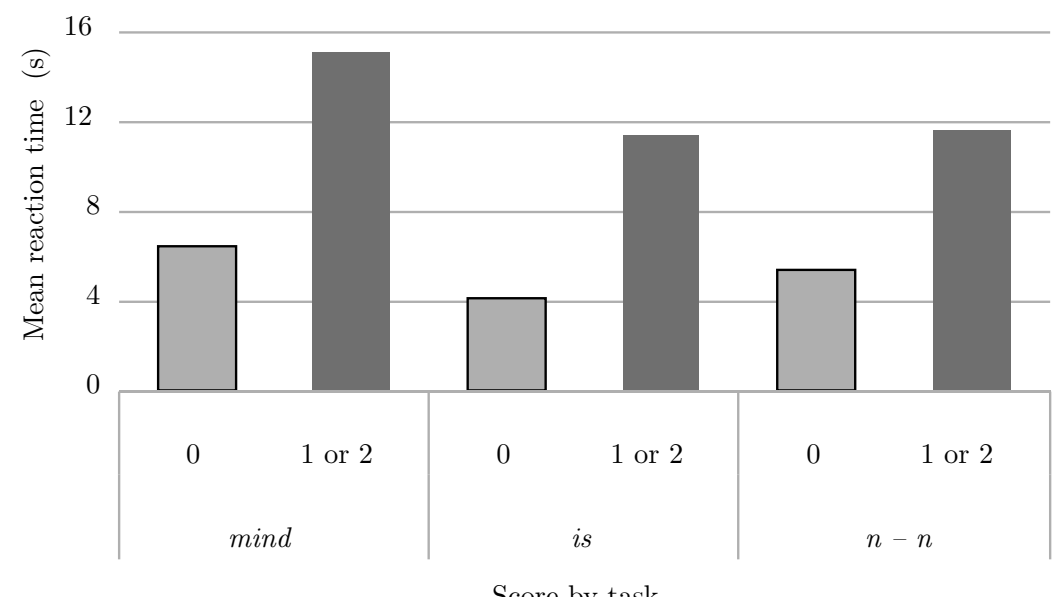

Score by task

Figure 7: Reaction times of answers achieving 1 or 2 scores and answers achieving no score

The three filler sentences, involving a numerically quantified expression and an indefinite, represent the type of distributive construction the interpretation of which was tested by Brooks and Braine (1996) and Syrett and Musolino (2013). These studies found that preschoolers from the age of 4 can access the distributive interpretations of such sentences. Our results confirm these findings: among the younger kids' answers to the fillers, the rate of incorrect solutions was merely $13 \%$; among the older kids' answers, it was $11 \%$. The 1 st graders only gave correct answers. The processing of the fillers confirms the role of age in processing distributivity. The average age of the children achieving at least 1 score with the filler sentences was $66.57(S D=8.6)$ months. The average age of those achieving no score was almost one year younger: $74.15(S D=11.6)$ months. The difference is significant: $F_{\mathrm{ANOVA}}(\mathrm{df}=1 / 100)=5.50, p=0.021$. 


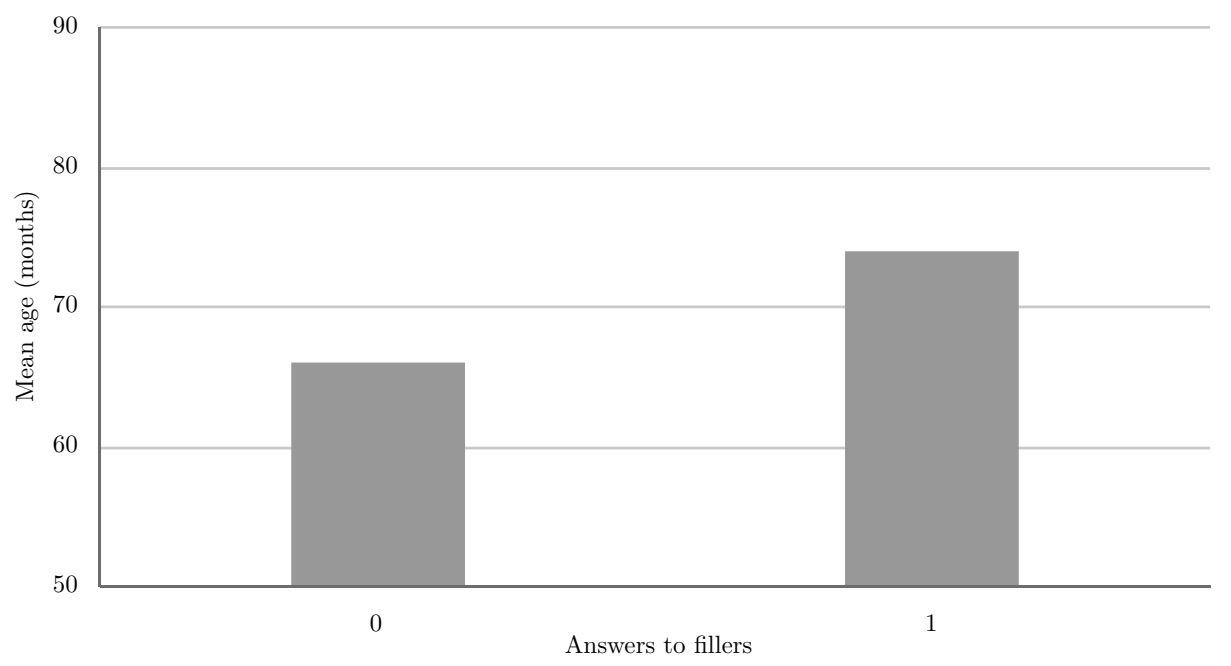

Figure 8: The mean age of the participants by the solutions of the fillers

\section{Discussion}

The results of our experiment have confirmed our initial hypothesis that children are capable of calculating the result of multiplication encoded by a doubly quantified sentence prior to receiving any training. The participants' success rate in calculating the result of multiplication was merely $30 \%$ around the age of 5 ; it was more than $50 \%$ around the age of 6 , and more than $70 \%$ around the age of 7 . This suggests that the ability to carry out multiplication with exact numbers in the number range below 10 becomes established between 5 and 7 years of age.

The three types of distributive constructions that we tested posed difficulties of different degrees. The distributivity marker that is easiest for children to recognize is mind 'every', the general universal quantifier of Hungarian. As shown by Figure 5, children are able to derive the distributive interpretation of sentences with mind 'every' a year before they learn the distributivity-marking functions of $i s$ and numeral reduplication.

For preschoolers, numeral reduplication is the hardest to interpret; but for first graders, it is just as easy to decipher as distributivity marked by mind. The apparent iconicity of numeral reduplication may initially be misleading; children have to learn that a duplicated numeral like háromhárom 'three-three' does not mean two copies of three; it means $x$ copies, where $x$ is a variable bound by a structurally more prominent quantifier. 
It also may contribute to the delay in the processing of numeral reduplication that numeral reduplication is much rarer than distributivity marking by means of a universal quantifier. In the material of the Hungarian Historical Corpus from the period 1950-2000 (www.nytud.hu/hhc/) there are 64 000 occurrences of mind 'every' (not counting the compounds containing mind), whereas the instances of numeral reduplication are less than 3000 . Apparently, by the age of 7 children learn that reduplication signals multiplication (rather than duplication), and from that time on the iconicity of the construction facilitates the triggering of distributive interpretation.

The processing of the distributivity marker is also proved to be more difficult for children than the processing of mind. Its difficulty may have two sources. Firstly, is, an enclitic, is not salient phonologically; secondly, it is ambiguous semantically. Its other, additive meaning, corresponting to 'too', requires a prejacent (see footnote 2), hence it is not expected to emerge in out-of-the-blue sentences; still it may be a disturbing factor.

Owing to the presence of these distributivity markers, the Hungarian sentence types that we tested are unambiguously distributive, and owing to the isomorphism of Hungarian grammar, they are also scopally disambiguated: their initial quantifier functions as the distributive key/ multiplier, and their second quantifier functions as the distributed share/ multiplicand. The children who answered the test questions correctly gave evidence of being able to identify the multiplier and the multiplicand, and to carry out the multiplication by calculating its product.

The children's answers also outlined the acquisition path of multiplication. As previous research (Brooks \& Braine 1996; Syrett \& Musolino 2013) showed and as the children's results with the filler sentences in our experiment have confirmed, the first stage of this path may be the recognition that a sentence containing a quantifier and an indefinite (e.g., Every woman is walking a dog) allows - or requires (depending on the context and the presence of a lexical element marking distributivity) - the multiplication of the referent of the indefinite.

The interpretation of doubly quantified sentences with a distributivity marker (such as Two women each are walking three dogs) involves additional difficulties. The child has to find out which quantifier is the multiplier and which one is the multiplicand. As the multiplicand is a set containing more than one member in most cases, its multiplication and the calculation of the sum of the multiple copies is also more challenging than the multiplication of a single object in sentences containing a single quantifier and an indefinite. 
Our experiment has shown that the procedure of multiplication can be carried out at three different levels of abstraction. The higher levels of abstraction represent more advanced stages of the acquisition of multiplication. The youngest children of those who can solve the task typically calculate the product of multiplication by multiplying the physical objects, and counting them afterwards. The next stage in the acquisition of multiplication is when children multiply sets of fingers, instead of sets of objects. First graders usually do not need the help of their fingers any more; they can multiply sets mentally.

These observations correlate in an interesting way with the finding represented in Figure 7, according to which correct answers took a much longer time to calculate than incorrect ones. Children giving incorrect answers did not go through the lengthy multiplication algorithm; they typically acted out the collective interpretation. Whereas carrying out the procedure of multiplication was a time-consuming process for most children, some first graders could answer immediately, apparently retrieving, rather than calculating, the result.

\section{Conclusion}

Our experiment has demonstrated that the distributive reading of doubly quantified sentences involves multiplication. The interpretation of this sentence type is part of the grammar of 6-7-year-old children; that is, children can perform multiplication prior to training. By the age of 7 , children can not only process the multiplicative interpretation of doubly quantified sentences but the majority of them can also actively calculate the product of multiplication.

It is a much discussed issue of developmental literature how to obtain evidence of intuitive multiplication; how to ensure that the mental operation elicited in experimental conditions is the complex procedure of multiplication rather than merely multiple addition. Studies devoted to the study of intuitive arithmetic suggest that evidence for intuitive multiplication should be sought for in children's ability to distinguish proportional relations between quantities and numerosities. We have argued that natural language provides a more direct testing ground: the distributive interpretation of sentences containing two numerical quantifiers. Doubly quantified sentences may also have collective and cumulative interpretations, however, there are various lexical and syntactic means to block these readings, and to enforce the distributive interpretation. The distributive interpretation of doubly quantified sentences involves a complex procedure 
which is identical with the algorithm that children learn to employ in solving multiplication problems at school. It consists of the identification of the multiplier and the multiplicand, the creation of as many copies of the multiplicand as the cardinality of the multiplier, and the addition of the copies of the multiplicand. What supplements this algorithm at elementary school for children older than the participants of our experiment is the memorization of the multiplication table, i.e., the memorization of the results of adding up multiple copies of the numbers to 10, which enables children to retrieve the product of multiplication instead of calculating it.

That 4-6-year-old preschoolers can passively understand the distributive interpretation of doubly quantified sentences has been shown by previous literature (Musolino 2009; É. Kiss et al. 2013; É. Kiss \& Zétényi 2017). What the present study has demonstrated is that by the age of $6-7$, children also become able to actively calculate the product of multiplication. We have also identified the acquisition path leading to this stage. Children first learn to multiply single individuals denoted by indefinite noun phrases (e.g., Three boys each got a candy). Then they learn to multiply sets denoted by numerically modified noun phrases (Three boys each got two candies). First they multiply and count sets of real objects, then sets of their fingers, and, eventually, they only perform mental calculations.

On a more general level, the results of our experiment contribute to the understanding of the role of language in numerical cognition. The discussion of this issue has so far focused on whether the availability of number words affects numerical cognition, including operations with exact and approximate quantities such as addition, subtraction and sharing (Wiese 2003; Gelman \& Butterworth 2005; Beller \& Bender 2008; Frank et al. 2008; Bender \& Beller 2013). Our results highlight the fact that language and mathematics are intertwined not only on the lexical level. Grammatical operations involving quantified expressions, among others, encode logical and mathematical operations on sets. Even if linguistic encoding is often ambiguous, grammatically encoded mathematical operations pave the way for abstract mathematics. The interpretation of certain grammatical configurations of numerically modified expressions supplemented with a lexical marker of distributivity enforces multiplication, hence children learn the algorithm of multiplication as part of language acquisition.

The study was carried out under the permission of the Ethical Commity of the Research Institute for Linguistics of the Hungarian Academy of Sciences and the parents of the children. 


\section{Acknowledgements}

This research was supported by grant 108951 of OTKA, the Hungarian National Scientific Research Foundation. The authors are grateful to the staff and kids of Betlehem and Halacska Kindergartens and the Érdi Street Primary School.

\section{References}

Barth, Hilary, Andrew Baron, Elisabeth Spelke and Susan Carey. 2009. Children's multiplicative transformations of discrete and continuous quantities. Journal of Experimental Child Psychology 103. 421-440.

Barth, Hilary, Lacey Beckmann and Elisabeth Spelke. 2008. Nonsymbolic, approximate arithmetic in children: Evidence for abstract addition prior to instruction. Developmental Psychology 44. 1466-1477.

Barth, Hilary, Kristen La Mont, Jennifer Lipton, Stanislas Dehaene, Nancy Kanwisher and Elisabeth Spelke. 2006. Nonsymbolic arithmetic in adults and young children. Cognition 98. 199-222.

Barth, Hilary, Kristen La Mont, Jennifer Lipton and Elisabeth Spelke. 2005. Abstract number and arithmetic in preschool children. Proceedings of the National Academy of Sciences 102. 14116-14121.

Beller, Sieghard and Andrea Bender. 2008. The limits of counting: Numerical cognition between evolution and culture. Science 319. 213-125.

Bender, Andrea and Sieghard Beller. 2013. Of adding oranges and apples: How non-abstract representations may foster abstract numerical cognition. Frontiers in Human Neuroscience 7. 1-4.

Boyer, Ty W., Susan C. Levine and Janellen Huttenlocher. 2008. Development of proportional reasoning: Where young children go wrong. Developmental Psychology 44. 1478-1490.

Brooks, Patricia J. and Martin D. S. Braine. 1996. What do children know about the universal quantifiers all and each? Cognition 60. 235-268.

Cantlon, Jessica F. and Elisabeth M. Brannon. 2007. How much does number matter to a monkey? Journal of Experimental Psychology: Animal Behavior Processes 33. 32-41.

Cordes, Sara and Elisabeth M. Brannon. 2009. Crossing the divide: Infants discriminate small from large numerosities. Developmental Psychology 45. 1583-1594.

Cordes, Sara, Charles R. Gallistel, Rochel Gelman and Peter Latham. 2007. Nonverbal arithmetic in humans: Light from noise. Perception \& Psychophysics 69. 1185-1203.

Dehaene, Stanislas. 1997. The number sense. Oxford: Oxford University Press.

É. Kiss, Katalin. 1991. Logical structure in syntactic structure: The case of Hungarian. In J. Huang and R. May (eds.) Logical structure and linguistic structure: Cross-linguistic perspectives. Dordrecht: Kluwer. 111-148.

É. Kiss, Katalin. 1994. Sentence structure and word order. In F. Kiefer and K. É. Kiss (eds.) The syntactic structure of Hungarian (Syntax and semantics 27). San Diego/New York: Academic Press. 1-90.

É. Kiss, Katalin. 2002. The syntax of Hungarian. Cambridge: Cambridge University Press. 
É. Kiss, Katalin. 2010. An adjunction analysis of quantifiers and adverbials in the Hungarian sentence. Lingua 120. 506-526.

É. Kiss, Katalin, Mátyás Gerốcs and Tamás Zétényi. 2013. Preschoolers' interpretation of doubly quantified sentences. Acta Linguistica Hungarica 60. 143-171.

É. Kiss, Katalin and Tamás Zétényi. 2017. Why is children's interpretation of doubly quantified sentences non-isomorphic. Linguistics 55. 1311-1336.

Flombaum, Jonathan I., Justin A. Junge and Marc Hauser. 2005. Rhesus monkeys (macaca mulatta) spontaneously compute addition operations over large numbers. Cognition 97. 315-325.

Frank, Michael C., Daniel L. Everett, Evelina Fedorenko and Edward Gibson. 2008. Number as a cognitive technology: Evidence from Pirahã language and cognition. Cognition 108. 819-824.

Gallistel, C. 1990. The organization of learning. Cambridge, MA: MIT Press.

Gallistel, Charles R., Rochel Gelman and Sara Cordes. 2006. The cultural and evolutionary history of the real numbers. In S. Levinson and P. Jaisson (eds.) Evolution and culture. Cambridge, MA: MIT Press. 247-274.

Gelman, Rochel and Brian Butterworth. 2005. Number and language: How are they related? Trends in Cognitive Sciences 9. 6-10.

Hunyadi, László. 1986. The expression of logical scope in Hungarian. On its syntax and semantics. In W. Abraham and S. de Meij (eds.) Topic, focus, and configurationality. Amsterdam \& Philadelphia: John Benjamins. 89-102.

McCrink, Koleen and Elisabeth S. Spelke. 2010. Core multiplication in childhood. Cognition 116. 204-216.

McCrink, Koleen and Karen Wynn. 2004. Large-number addition and subtraction by 9month-old infants. Psychological Science 15. 776-781.

McCrink, Koleen and Karen Wynn. 2007. Ratio abstraction by six-month-old infants. Psychological Science 18. 740-746.

Musolino, Julien. 2009. The logical syntax of number words: Theory, acquisition and processing. Cognition 111. 24-45.

Nunes, Terezinha, Analucia Schliemann and David Carraher. 1993. Street mathematics and school mathematics. Cambridge: Cambridge University Press.

Pagliarini, Elena, Gaetano Fiorin and Jakob Dotlačil. 2012. The acquisition of distributivity in pluralities. In A. K. Biller, E. Y. Chung and A. E. Kimball (eds.) Proceedings of the 36th Annual Boston University Conference on Language Development (BUCLD). Somerville, MA: Cascadilla Press. 387-399.

Schlottmann, Anne and Jane Tring. 2005. How children reason about gains and losses: Framing effects in judgement and choice. Swiss Journal of Psychology 64. 153-171.

Slaughter, Virginia, Dorian Kamppi and Jessica Paynter. 2006. Toddler subtraction with large sets: Further evidence for an analog-magnitude representation of number. Developmental Science 9. 33-39.

Surányi, Balázs. 2002. Multiple operator movements in Hungarian. Doctoral dissertation. LOT, Utrecht.

Surányi, Balázs. 2006. Quantification and focus in negative concord. Lingua 116. 272-313.

Syrett, Kristen and Julien Musolino. 2013. Collectivity, distributivity, and the interpretation of numerical expressions in child and adult language. Language Acquisition 20. 259-291. 
Szabolcsi, Anna. 1994. All quantifiers are not equal: The case of focus. Acta Linguistica Hungarica 42. 171-187.

Szabolcsi, Anna. 1997. Strategies for scope taking. In A. Szabolcsi (ed.) Ways of scope taking (SLAP 65). Dordrecht: Kluwer. 109-154.

Szabolcsi, Anna and Michael Brody. 2003. Overt scope in Hungarian. Syntax 6. 19-51.

Wiese, Heike. 2003. Numbers, language, and the human mind. Cambridge: Cambridge University Press.

Wynn, Karen. 1992. Addition and substraction by human infants. Nature 358. 749-750.

$\mathrm{Xu}$, Fei and Elisabeth Spelke. 2000. Large number discrimination in 6-month-old infants. Cognition 74. B1-B11. 
